\title{
Care of elderly people by the general practitioner and the geriatrician in Belgium: a qualitative study of their relationship
}

This article was published in the following Dove Press journal:

Journal of Multidisciplinary Healthcare

24 January 2012

Number of times this article has been viewed

\author{
Isabelle Dagneaux' \\ Isabelle Gilard ${ }^{2}$ \\ Jan De Lepeleire ${ }^{3}$ \\ 'Chair of General Medicine, Faculty \\ of Medicine, Catholic University \\ of Louvain, Belgium; ${ }^{2}$ Geriatric Day \\ Hospital, Cliniques Universitaires \\ Saint Luc, Catholic University of \\ Louvain, Belgium; ${ }^{3}$ Department \\ of General Practice, Katholieke \\ Universiteit Leuven, Belgium
}

Objectives: The care of elderly people is a large part of a general practitioner's work. The growing elderly population means that the medical community must give thought to the management of their care. Within this large field, we focused on the relationship between general practitioners and hospital geriatricians.

Methods: Focus group discussions were performed to describe the collaboration between general practitioners and hospital geriatricians: four of these focus groups contained only general practitioners, two groups contained only hospital geriatricians, and one group was made up of general practitioners and hospital specialists. Participants were invited to speak about bad or good experiences of intercollaboration. The discussions were recorded, transcribed, and coded.

Results: An important regional disparity was observed: better relationships and easier collaboration were reported in those regions that benefit from a wider range of geriatric services. In areas with few geriatric services, doctors knew little of other professionals and reported suspicion and even conflicts. Positive experiences and communication favor good relationships.

Conclusions: The collaboration between general practitioners and hospital geriatricians should be enhanced: information, exchanges, and reflection on roles and competencies are essential.

Keywords: geriatrics, general practitioner, collaboration, qualitative research, elderly

\section{Background}

In Western countries, the elderly population is growing and the challenge of providing front-line health care to elderly people is a major challenge for health care systems. General practitioners (GPs) are at the heart of front-line health care. The transition from home to hospital (and vice versa) is a particularly delicate moment for the elderly, and questions arise about coordination between health care levels and locations. It is easier for GPs to request supplementary tests or global reviews for their elderly patients within 1 day. ${ }^{1}$ Hospital release is not always experienced in a positive way by GPs.

With the development of the specialty of geriatrics, frail elderly individuals are provided a specialized health care location within the hospital. The Royal Belgian decree (January 29, 2007; specifies the organization of a geriatric program [hospitalization, internal and external advice, consultation and geriatric day hospital], the definition of the geriatric patient, the role of the GP, the role and composition of the multidisciplinary geriatric team. For details, see: http://www.ejustice.just.fgov.be/doc/rech_f.htm), favors the development of geriatric day hospitals and specifies their functioning. This permits the drawing up of a wide-ranging report for an elderly person while avoiding the need for a hospital stay of several days or several trips to and from home for tests.
Correspondence: Isabelle Dagneaux Centre académique de Médecine Générale, Avenue E. Mounier, 53 bte BI.53.I I, I 200 Brussels, Belgium Tel +32 27645344 Fax +32 27645327

Email isabelle.dagneaux@uclouvain.be 
Numerous carers of various disciplines (as well as in patients' home care) take part in the assessment, but the focus in the current paper will be on the medical collaboration. Within this structure, how do the doctors from first- and second-line health care collaborate?

The relationship between GPs and hospital geriatricians (HGs) specifically has not been widely studied. A comprehensive review of the literature concerning relationships between GPs and specialist doctors revealed that studies have dealt with several questions. Admission letters ${ }^{2-5}$ have been studied from the aspects of content, support, lack of elements considered to be important etc, as have discharge letters ${ }^{4,6}$ in which content, support, time to reach the addressee etc, were studied. The means of communication ${ }^{7}$ used were examined, with these consisting of letters, telephone conversations, direct contact, or the holding of a preparatory meeting for discharge. ${ }^{8}$ The issue of a common admission policy ${ }^{4,9-13}$ questioned the definition of common criteria or guidelines, while studies have addressed the knowledge and/or recognition of respective skills..$^{14,15}$ Some articles offer a reflection on the first-/second-line interface: ${ }^{16-21}$ what kind of communication, how to improve the communication, oriented by specialty: ophthalmology, ${ }^{22}$ psychiatry, ${ }^{23}$ palliative care, ${ }^{24}$ gastroenterology, ${ }^{25}$ or diabetology. ${ }^{26}$ Particularly, Kvamme and colleagues ${ }^{17}$ advocate, among other things, an improvement in the quality of health care at the interface between GPs and specialists, the importance of envisaging shared approaches to health care and the division of tasks, of defining common guidelines, and discussing the patient's prospects.

In another viewpoint, the experience of the patient at the first-/second-line health care interface was studied as an indicator of the quality of the health system. ${ }^{27,28}$ Improving the collaboration between health care professionals at this interface undoubtedly has a socioeconomic impact, but there are little data available about this. Fenton and his colleagues "evaluated the health utilization impacts of an innovative intervention emphasizing chronic disease self-management and physical activity promotion among frail elders in primary care ${ }^{29}$ and showed a reduction in costs.

Some articles about the collaboration between GPs and hospital specialists take a qualitative viewpoint. In a Canadian study, ${ }^{30}$ family doctors noted 11 challenges for improving satisfaction linked to their work, with "respect by specialists" being an important challenge. One of the solutions proposed to achieve this was "to create and develop relationships between FPs and other specialists and to support each other's roles" and to "enhance the profile of family medicine in universities and teaching hospitals". ${ }^{30}$ In the same way, Thind et al showed ${ }^{31}$ that good collaboration with specialists is one of the factors which increases the satisfaction of GPs. They show that it is essential to promote meetings between GPs and specialists in order to achieve greater knowledge and/or recognition of their respective skills and roles, as well as satisfactory collaboration.

A recent qualitative study on the infrequent use of geriatric day hospitals by GPs was carried out by our colleagues in Gent and Liège. ${ }^{32}$ They highlight the frustration GPs may feel when they are not involved in decisions concerning the organization of the health care system or the care provided to their patients, their feeling of being threatened by and in competition with specialists, and the GPs lack of knowledge and experience with regard to geriatric day hospitals. They conclude that there is a need to develop a culture of trust and mutual respect between health care professionals.

The aim of the current research is to examine collaborations between GPs and HGs regarding elderly patients. A better collaboration seems to be needed, but very little is known about actual interactions between GPs and HGs and possibilities for improving these.

The research questions which arise are:

1. How do GPs and HGs currently collaborate?

2. What are the problems encountered, and what are the possibilities for a better collaboration?

\section{Method}

A regional group of GPs in the east of Belgium showed interest in this study, following a survey carried out in their area regarding tools to be developed for the health care of elderly people. ${ }^{1}$ With them, the issue of collaboration between GPs and HGs was addressed. Focus group discussions (FGDs) were the preferred method as these encourage participants to express their perceptions and discuss their interactions. ${ }^{33}$ Moreover, FGDs are a good method to explore a little known and/or complex topic. ${ }^{34}$ First, GPs and HGs met in separate FGDs. The homogeneity of the groups encouraged each individual to express themselves, all the more so if these were groups of individuals who already knew each other and regularly met for ongoing medical training. Only the last group brought together GPs and hospital specialists, which permitted the observation of new interactions and reactions with regard to the data obtained in the preceding FGDs. Most of the groups were formed in this eastern, rural region of Belgium because of the existing close collaboration and their interest in this work. For the sake of comparison, a discussion was held with GPs from a city, in another region 
of the country (one FGD). The HGs (two FGDs) came from different regions of French-speaking Belgium, given their small number.

The FGDs took place between November 2008 and May 2009. They were moderated by a research doctor who was not involved in the investigation (Dr Jean-Marc Feron), following an interview guide with open-ended and semi-structured questions. The script of the FGDs was drafted by the two main researchers (Dagneaux and Gilard) and revised by De Lepeleire and by experts in qualitative research, with both GPs and HGs.

After the introductory questions, the discussion was structured with the following questions:

- Have you had a bad experience of collaboration with a HG/GP, or even a conflict? Could you tell us about it and specify what happened?

- Have you had a positive experience? It can provide interesting elements for building collaboration.

The two main researchers were present as observers. The discussions were recorded, transcribed in full, and anonymized. The first three FGDs were analyzed independently by the three authors, following the principles of grounded theory: ${ }^{35}$ open-ended coding was applied to the text, within the boundaries formed by the research questions. The researchers met several times to determine a common list of codes. The other FGDs were then analyzed. Weft QDA freeware (v 1.0.1) was used for the organization and retrieval of quotes and codes. The analysis of the contents of the discussions showed that data saturation was achieved at the end of seven FGDs.

A first level of analysis highlighted twelve codes and five sub-codes:

- communication

$\circ$ exchange

$\circ$ phone

$\circ$ letters

$\circ$ meeting
- skill

$\circ$ vision for the patient

- complementarity

- trust

- conflict

- experience

- generation

- information

- organization

- relation to three (GP-HG-patient)

- region - cultural

- legal structure.

By analyzing the data in each category (code or sub-code) and by comparing them, hypotheses were inductively formulated to answer the research questions ("grounded theory"). The words of the selected quotes were taken into account, as was the context of statement (specialty, work location, age, and experience of the speaker, etc) and more general ideas expressed in the group. ${ }^{35}$ Six themes emerged from the analysis.

\section{Ethics}

The participants were informed about the purpose of the study, about the methodology, and in particular about the recording of the FGDs. All participants gave their oral consent to the procedure. The data were anonymized during the transcription, and the recordings were erased after transcription. The results were presented to the participants of the FGDs.

\section{Results}

The composition of the focus groups is specified in Table 1.

Six themes emerged from the analysis. Quotes are given to illustrate some dimensions of each theme. For each quote, it is specified which FGD it was extracted from (FGD 1-7) and the specialty of the speaker (GP, HG, or specialist).

Table I Composition of focus groups

\begin{tabular}{llllllll}
\hline$N^{\circ}$ FG & Medical specialization & Location & Date & Number of participants & Men & Women & Average age \\
\hline I & HG & Urban & $20 / I 1 / 2008$ & 9 & 2 & 7 & 38 \\
2 & GP & Rural & $13 / 02 / 2009$ & 12 & 8 & 4 & NC \\
3 & GP & Urban & $9 / 03 / 2009$ & 14 & 8 & 6 & 37 \\
4 & GP & Rural & $10 / 03 / 2009$ & 7 & 6 & 1 & 57 \\
5 & HG & Mixed & $16 / 03 / 2009$ & 12 & 5 & 7 & 46 \\
6 & GP & Rural & $31 / 03 / 2009$ & 19 & 9 & 10 & 43 \\
7 & Specialists + GP & Rural & $12 / 05 / 2009$ & $12 *$ & 9 & 3 & 49 \\
Total & & & 85 & 47 & 38 & 45 \\
\hline
\end{tabular}

Note: *Of which 3 male specialists.

Abbreviations: GP, general practitioner; HG, hospital geriatrician. 


\section{Regional disparity}

GPs have different viewpoints as their practices are located in different regions of the study.

The proximity of several services existing in a city permit a collaboration which takes into account human and relational factors. The deficit in service provision makes the difficulties which may arise (relationship, organizational, communications, etc) all the more pronounced.

In the rural area, a GP said: "We don't have a choice, there's only the hospital in Y." (FGD2-GP)

The experience is different in the city where there are several hospitals and geriatric services: "Having said that ... speaking for myself, if I have patients where I don't entirely agree, where I find that I'm well-received by the geriatrician or ... I nevertheless sometimes have a tendency to influence patients towards going to this or that institution. I ... I think that even if there's a record ... if I'm convinced that the patient will be treated better elsewhere, in any case ... I think that I can influence him or her with regard to the hospital. Because in any case, many of our patients say 'Doctor, you know best ...'” (FGD3-GP)

\section{Generation effect}

The age of the participants is a determining factor for the perception of collaboration. Geriatrics is a "young specialty", which is poorly known and which must still prove its relevance to GPs. It appears that the initial reticence fades, thanks to time, good experiences, and common formation classes for the last generations. Young doctors are more inclined to collaborate.

A HG thinks that it will take time to make the geriatric specialty better known: “. .. so I think that it will take one or two generations until ..." (FGD5-HG)

Speaking about contact with GPs, a HG said: "It's true that I think that it's also a generation question." (FGD1-HG)

\section{Perception of collaboration}

HGs give the impression that they are used to working with GPs, while the reverse is rarely true. Most GPs feel that they receive little recognition from HGs (cf. competence role) and have little familiarity with them (cf. experience), while HGs say that they pay attention to the manner of communicating with GPs and seek to inform them of their services.
A HG talks about his relations with GPs:

"But you see how much tact we used? Where no specialist steps in like that ... a cardiologist isn't going to have any qualms about giving a statin to an 85-year-old patient. And so he won't ask for authorization, so ultimately there is humanity in geriatrics which you don't find in other specialties and we still apologize!" (FGD5-HG)

The GPs often regret being little involved in decisions which concern their patients:

"There are sometimes some placing decisions or things like that which are taken without them consulting or asking us or ... in my opinion, the doctors here have taken the decision to place the patient and we find ourselves facing a fait accompli, although we are much closer to the patient, we are much more ..." (FGD2-GP)

\section{Experience of collaboration}

GPs who make little use of geriatric services are also the ones who least recognize its utility. When they are personally familiar with the work of a geriatrics team, they are more inclined to recognize its added value.

A GP has doubts about the specific interest of a geriatric service in comparison with an internal medicine service:

"I don't think that I have already hospitalized an elderly person within a geriatrics service. I admit them and they then end up in a geriatrics service ... I would have to confess to you that when I have an elderly person who is admitted for an intestinal problem, I prefer ... I would prefer that he or she goes to gastroenterology than to geriatrics. But we are often overtaken by decisions, 'Oh, 82 years old, well geriatrics it is'. I think that people are better treated for their principal problem in a sharp cardiology, gastroenterology department, etc." (FGD2-GP)

A HG thinks that a previous good experience opens the door to a good collaboration:

"I think that with a certain number of general practitioners, collaboration is already well advanced. They already know us before hospitalization and have also taken part in several meetings at the hospital. And so I think that they have sent people and have then had positive responses and carry on doing so." (FGD5-HG)

\section{Exchange of information}

The GP has essential information concerning the patient's past, home and social environment. The HG provides other expertise. It is essential for information to circulate. The media for this exchange of information are the telephone, letters, and meetings. 
"Giving information or asking for it, taking joint decisions ..." (FGD1-HG)

A GP has experienced good collaboration with a geriatric service: "This is the place where I have the most communication, you have the feeling that you're genuinely doing joint work, we take note of each other's point of view. It's very, very important that there is a set of details with which we are familiar and the information which we can give and in return $I$ have a maximum amount of information on what we can still do to help a fragile person.” (FGD3-GP)

Another GP is disappointed not to be involved: "So I think that the least thing was to telephone the attending doctor, to know what you think about it ... what we all think about it and so on. That wasn't done, so there is nevertheless a lack of communication." (FGD2-GP)

A HG recognizes the importance of such information exchange: "They confide in us with their concerns and can already give us a fair amount of information on the patient's past, his current condition and general situation." (FGD1-HG)

\section{Acknowledgment of competences and roles}

An important finding of the study is the difficulty in recognizing the specific roles and competences of each professional.

On several occasions, GPs reported (or it was relayed by HGs) that they are afraid that the HGs would take their place, play their role, or keep their patients.

A HG relays this fear: "What I've heard tens and hundreds of times is: "The gynecologists have taken away our women, the pediatricians have taken away our children and if the geriatricians take away the elderly, there won't be anyone else left." I've heard this a non-negligible number of times ..." (FGD1-HG)

A GP talks about geriatric consultations: "I still don't understand why geriatricians need to see everyone two or three months later ... inspection visits ... as well as to see whether the patient is doing well." (FGD2-GP)

Many GPs are not aware of what the HG (and his team) can contribute.

"And frankly on this, we have the impression that ... they are performing our role." (FGD2-GP)

"I'd say that in general geriatrics, we do it ourselves as general practitioners except for the technical actions which we don't know how to do." (FGD2-GP)
They do not know either the exact role of the $\mathrm{HG}$, or the functioning of the legal structures.

A GP who has had a positive experience of the geriatric day hospital explains to the others: "Now it is necessary to say also that the INAMI obliges these centers there to get with the general practitioners." (FGD2-GP)

And conversely, they often have the impression that their competence isn't acknowledged.

"When there are too many items of advice in the social plan, I tell myself that I'm really being treated like an idiot ... When they tell me: You have to take up the doormats and things like that, in general, you've already thought of it yourself, but perhaps it's me being sensitive, and my paranoid side, but this annoys me a bit, I think that we've often already taken measures like that, but against this it's perhaps better to summarize them." (FGD6-GP)

HGs often distinguish themselves from their hospital colleagues by their global treatment of the patient. This is also how GPs define themselves, making a differentiation of roles more difficult.

"And what I understood from a general practitioner colleague was that he said that basically you are like us ... you feel responsible for the patient as a whole, which is both a compliment ... but at the same time, this was also a way of saying, but you know, we know how to do that too." (FGD5-HG)

These common competences undoubtedly cause fear of confusion about roles. This is above all the case among GPs. Consequently, a simple differentiation of roles is made as a function of the territory of each one: homes for the GPs, and hospital for HGs.

"I nevertheless think that the first difference is in terms of location, isn't it? ... Indeed, this is the hospital for geriatricians and the home for general practitioners and somewhere, they really do the same work and ideally, they should ... should really perceive problems in the same way, together ... at their location ..." (FGD3-GP)

But undoubtedly, it is necessary to look further for complementarities. HGs are mainly convinced of the shared health care approach:

\footnotetext{
"We approach a discussion with a need for an enlightened opinion on the home situation, also because we (certainly) realize that a hospitalized patient is not the patient known
} 
to the attending doctor. And I think that these are two very different lights.” (FGD1-HG)

The last FGD (FGD7) was very different from the others: it was obvious that GPs and hospital specialists were accustomed to speaking to each other, and the discussion showed mutual respect and tact. A part of this group used to meet for several years to address collaboration and shared health care approaches at a local level (SYLOS project). ${ }^{36}$ They don't agree with the perception that there is a conflict in their roles:

"There is not this conflict of skills, here. It is necessary to make the things that each can make with the possibilities that he has to make it. And the hospital is made to make things which the general practitioners cannot make. If they can make it, well, they made it at home, that it is completely true. (...) if the general practitioner refers a patient, it is to facilitate the matter, so that we, the specialists, serve as intermediary to make this or that. (...) The general practitioners are going to take advantage of that, as they will have a second opinion which is different from theirs (...) If it is not to make that, it makes no sense." (FGD7-specialist)

\section{Discussion}

\section{Major findings}

The study of collaboration between HGs and GPs shows that collaboration exists, with numerous attempts and certain difficulties. These difficulties appear to be due to a lack of information, bad past experiences which have not been overcome, erroneous beliefs, and a lack of positive experiences. To answer our first research question (How do GPs and HGs currently collaborate?), the lack of recognition has to be underlined. Indeed, collaboration requires one to feel confident, ie, to at least know the other doctor and feel recognized for one's own work and skills. To answer our second research question (What are the problems encountered, and what are the possibilities for a better collaboration?), we suggest that every opportunity must be taken to favor meetings and exchanges so that collaboration can develop better.

The disparities observed between regions and according to the generation effect strengthen this interpretation. The possibility of choice of geriatric service in a big city seems to facilitate the collaboration: it shows how much it is necessary to take human factors into account; the structure's implementation is not enough.

A lot of GPs are afraid that the HGs will take their place, play their role, and keep their patients. However, the younger generations seem to be used to collaborating and suffer less fear of competition. These reactions are astonishing given the low number of trained HGs within the country ( 180 HGs within Belgium) and the growth in the elderly population. Moreover, the GP is legally given the central role in caring for elderly patients: he must prescribe the global evaluation, and the proposed care plan must be addressed to him. These elements are intended to strengthen collaboration. They are not only legal requirements but are also pragmatic: there is no point in starting long-term treatment at the hospital if there is no follow-up at home with the same health care intention. It appears that geriatrics is a "young specialty" which is poorly known and which still has to demonstrate its relevance to GPs. This highlights the difficulty in recognizing the specific roles and competences of each specialty.

HGs and GPs have a great deal in common: a global vision of the patient and his/her surroundings, concern for living conditions, and integration of the different components of a patient's health. This needs to be discussed, and a local- and national-level study of the recognition of roles and competences and the sharing of tasks appears to be essential.

The current study did not aim to change attitudes among the participants. It is nevertheless possible to observe that it caused some changes, or least promoted reflection: information was received with interest, an individual or collective reflection process on the quality of health care was initiated, and a group decided to pursue the discussion with the data we gave them.

\section{Comparison with literature}

The results of our study intersect with the reflection by Kvamme and colleagues ${ }^{17}$ (cf. introduction). As advocated by Kvamme et al, the shared health care approach appears to be essential for good collaboration, and needs concrete means (meetings, communication, etc) to define common objectives. Our work is supported by the Canadian study ${ }^{30}$ mentioned above, about GPs asking for "respect by specialists", and by the study of Thind and his colleagues ${ }^{31}$ who showed that good collaboration with specialists is one of the factors which increases the satisfaction of GPs. These studies and our work show that it is essential to promote meetings between GPs and specialists in order to achieve greater knowledge and a better recognition of their respective skills and roles, as well as satisfactory collaboration. The last focus group confirmed this conclusion, showing the fruits of communication and meetings between GPs and specialists which have been progressing for several years.

The recent qualitative study carried out in Belgium ${ }^{32}$ on the infrequent use of geriatric day hospitals by GPs concluded 
that the development of a culture of trust and mutual respect between health care sectors would be beneficial. These observations and conclusions broadly corroborate our own findings. Moreover, the current study took into account the viewpoint of HGs and highlighted the difference in perceptions between GPs and HGs. The efforts of HGs to make themselves known and our analysis regarding the problem of roles and skills may constitute an initial response to their practical propositions ("implications for practice").

Several articles cite communication media between the two lines of health care (cf. introduction). These are important, but above all, it is a question of knowing to which end they are used. The resources exist, and they will be used in favor of a relationship if it exists in a positive way: a GP who knows a HG will often not hesitate to call him to ask his opinion, or to refer a patient to him, and vice versa (cf. the paragraph on "exchanges").

\section{Strengths and limitations of the study}

Several strengths of this study can be underlined. First of all, it was carried out with HGs and GPs who were concerned by the issue. The use of appropriate discussion and communication methods allowed each participant to express his viewpoint and perception of collaboration. The FGDs, which were initially distinguished by specialty, permitted participants to openly express their views. For its part, the last focus group allowed the observation of a discussion between GPs and specialists who have a longstanding history of dialog. Lastly, the study highlights the regional realities of a national program: the general objective and its application on the ground will diverge depending on the local characteristics of the organization of health care and the relationships between health care providers.

One of the limitations was the particular location of the study, which does not permit a generalization to national level. Another limit is that only doctors were met in the FGD, while a multidisciplinary care team is involved in elderly care, at home as in the hospital. Moreover, the study focused on the perception of collaboration among the doctors as opposed to effective collaboration, or the way in which it actually develops. Nor was the opinion of the patients taken into account - their perception of collaboration between health care professionals at different levels, or the consequences of this collaboration on health care and health, would also be of interest.

\section{Prospects}

Research questions remain or have been highlighted by the current study. Future research should focus on the effectiveness of collaboration (and not only the perception of collaboration), eg, on release from hospital. It would also be interesting to take the viewpoint of the different carers at the interface between health care lines into account, including the multidisciplinary care team, the patient, and his/her family. The consequences of an improved collaboration can be studied, including the socioeconomic impact, health and well-being of the patient, and satisfaction of the family.

In terms of organization of the health care system, several concrete suggestions can be made:

- Every opportunity must be taken by health care professionals to inform themselves, meet their colleagues, and carry out exchanges. A visit to a hospitalized patient, a hospital meeting with or without the family, and continuous training are opportunities for doctors (GPs and HGs) to get to know their colleagues.

- To date, HGs defined themselves above all in contrast to their hospital colleagues, as they insist on being involved in the global care of their elderly patients. GPs also define themselves in these terms, thus making it difficult to differentiate their respective roles. There is a great deal of work to be done in defining roles and skills, both in geriatrics and in general medicine.

- GPs may be confident of their capacity to take care of their elderly patients. Collaboration with a HG does not call this competence into question but offers them another view of the situation.

- Geographical proximity is a key factor for a geriatric day hospital (this item also emerged from our 2007 survey). ${ }^{1}$ The organization of health care at the national level must offer scope for close and easy collaboration, both for GPs and for patients.

\section{Conclusion}

The issue of relationships between GPs and specialist doctors, more specifically in the context of health care for the elderly, appears to highlight a great deal of resentment, but also much hope. The study resulted in a process of reflection about collaboration.

The study focused on the perception of collaboration by doctors at the interface of primary and secondary health care lines surrounding the geriatric patient. The Royal Decree of 29 January 2007 is interesting, but it remains little known among GPs. Current regional disparities in the provision of geriatric care highlight the role of human factors in the collaboration. Taking these factors into account can allow the health care program for geriatric patients to function better. Collaboration between the two health care lines must 
be improved: meetings and exchanges must be promoted to achieve greater recognition of the skills and roles of each individual.

Studies which take an interest in the experience of a patient and his family at the point of transition from first to the second line of health care and of return to hospital would be relevant, as would others concerned with the viewpoint of other non-medical home carers. Certain methods allow the effective observation of collaboration - and not only the perception of involved doctors - as, for example, a field study. This would be rich in lessons to help understand better the challenges of intercollaboration.

\section{Disclosures}

Dagneaux and De Lepeleire are GPs. Gilard is a hospital geriatrician, responsible for the Geriatric Day Hospital in the Cliniques Universitaires St Luc in Brussels, Belgium. The authors report no conflicts of interest in this work.

\section{References}

1. Dagneaux I, Vercruysse B, Degryse J-M. [Survey: GP and elderly: Catholic University of Leuven]; 2007:58. French.

2. Lindström K, Hagman A, Berg L, Bengtsson C. Referral notes used as a tool for evaluating the co-operation between general practitioners and hospital physicians. Scand J Prim Health Care. 1994;12(3):214-218.

3. Bowling A, Redfern J. The process of outpatient referral and care: the experiences and views of patients, their general practitioners, and specialists. Br J Gen Pract. 2000;50(451):116-120.

4. Garåsen H, Johnsen R. The quality of communication about older patients between hospital physicians and general practitioners: a panel study assessment. BMC Health Serv Res. 2007;7:133.

5. Ong SP, Lim LT, Barnsley L, Read R. General practitioners' referral letters - Do they meet the expectations of gastroenterologists and rheumatologists? Aust Fam Physician. 2006;35(11):920-922.

6. Lane N, Bragg MJ. From emergency department to general practitioner: evaluating emergency department communication and service to general practitioners. Emerg Med Australas. 2007;19(4):346-352.

7. Farquhar MC, Barclay SI, Earl H, Grande GE, Emery J, Crawford RA. Barriers to effective communication across the primary/secondary interface: examples from the ovarian cancer patient journey (a qualitative study). Eur J Cancer Care (Engl). 2005;14(4):359-366.

8. Ranmuthugala G, McInnes E, Mira M, Rendalls S, Atkin N, Kennedy P. A pre-discharge project - does GP willingness equal involvement? Aust Fam Physician. 1997;26 Suppl 2:S104-S108.

9. Donohoe MT, KravitzRL, Wheeler DB, Chandra R, Chen A, Humphries N. Reasons for outpatient referrals from generalists to specialists. J Gen Intern Med. 1999;14(5):281-286.

10. Forrest CB, Nutting PA, Starfield B, von Schrader S. Family physicians' referral decisions: results from the ASPN referral study. J Fam Pract. 2002;51(3):215-222.

11. Grimshaw JM, Winkens RA, Shirran L, et al. Interventions to improve outpatient referrals from primary care to secondary care. Cochrane Database Syst Rev. 2005;3:CD005471.

12. Man-Son-Hing M, Power B, Byszewski A, Dalziel WB. Referral to specialized geriatric services. Which elderly people living in the community are likely to benefit? Can Fam Physician. 1997;43:925-930.

13. McLean KA, Austin CA, Neal KR, Channer KS. Integration between general and geriatric medicine: a needs related policy. $J R$ Coll Physicians Lond. 1994;28(5):415-418.
14. Cram P, Ettinger WH Jr. Generalists or specialists - who does it better? Physician Exec. 1998;24(1):40-45.

15. Lökk J, Nilsson M, Norberg B, Hultdin J, Sandström H, Westman G. Vitamin B12 in primary health care and geriatrics - attitudes, knowledge and competence. Int J Geriatr Psychiatry. 2001;16(10): 987-992.

16. Koole R. Interaction between dentists, general practitioner and medical specialist. Ned Tijdschr Tandheelkd. 2001;108(6):213-215. Dutch.

17. Kvamme OJ, Olesen F, Samuelson M. Improving the interface between primary and secondary care: a statement from the European Working Party on Quality in Family Practice (EQuiP). Qual Health Care. 2001;10(1):33-39.

18. McLain BR. Collaborative practice: a critical theory perspective. Res Nurs Health. 1988;11(6):391-398.

19. Mimbela Sánchez MM, Foradada Baldellou S. An analysis of the interrelations of primary care-specialized care in patient referral. Aten Primaria. 1993;12(2):65-68, 70. Spanish.

20. Redfern J, Bowling A. Efficiency of care at the primary-secondary interface: variations with GP fundholding. Health Place. 2000;6(1): $15-23$.

21. Smith SM, Allwright S, O'Dowd T. Effectiveness of shared care across the interface between primary and specialty care in chronic disease management. Cochrane Database Syst Rev. 2007;3:CD004910.

22. Riad SF, Dart JK, Cooling RJ. Primary care and ophthalmology in the United Kingdom. Br J Ophthalmol. 2003;87(4):493-499.

23. Strathdee G. Primary care-psychiatry interaction: a British perspective. Gen Hosp Psychiatry. 1987;9(2):102-110.

24. Brenneis $\mathrm{C}$, Bruera $\mathrm{E}$. The interaction between family physicians and palliative care consultants in the delivery of palliative care: clinical and educational issues. J Palliat Care. 1998;14(3):58-61.

25. Cardin F, Franco-Novelletto B, Fassina R, Sturniolo G. How do general practitioners rate their relationship with gastroenterologists? Dig Liver Dis. 2004;36(5):315-321.

26. Constantino M, Hoskins PL, Fowler PM, et al. Interaction between diabetic patients, their general practitioners and a hospital diabetic clinic. Med J Aust. 1991;155(8):515-518.

27. Baker R, Preston C, Cheater F, Hearnshaw H. Measuring patients' attitudes to care across the primary/secondary interface: the development of the patient career diary. Qual Health Care. 1999;8(3):154-160.

28. Preston C, Cheater F, Baker R, Hearnshaw H. Left in limbo: patients' views on care across the primary/secondary interface. Qual Health Care. 1999;8(1):16-21.

29. Fenton JJ, Levine MD, Mahoney LD, Heagerty PJ, Wagner EH. Bringing geriatricians to the front lines: evaluation of a quality improvement intervention in primary care. J Am Board Fam Med. 2006;19(4): 331-339.

30. Manca D, Varnhagen S, Brett-MacLean P, Allan GM, Szafran O. Respect from specialists: concerns of family physicians. Can Fam Physician. 2008;54(10):1434-1435, 1435. e1-e5.

31. Thind A, Freeman T, Thorpe C, Burt A, Stewart M. Family physicians' satisfaction with current practice: what is the role of their interactions with specialists? Healthc Policy. 2009;4(3):e145-e158.

32. Vanden Bussche P, Desmyter F, Duchesnes C, et al. Geriatric day hospital: opportunity or threat? A qualitative exploratory study of the referral behaviour of Belgian general practitioners. BMC Health Serv Res. 2010;10:202.

33. Lakshman M, Charles M, Biswas M, Sinha L, Arora NK. Focus group discussions in medical research. Indian J Pediatr. 2000;67(5): 358-362.

34. Pope C, Mays N. Reaching the parts other methods cannot reach: an introduction to qualitative methods in health and health services research. BMJ. 1995;311(6996):42-45.

35. Pope C, van Royen P, Baker R. Qualitative methods in research on healthcare quality. Qual Saf Health Care. 2002;11(2):148-152.

36. Unger J-P. [The local health systems (SYLOS). A process of action research to improve coordination between hospital and general practitioners.] Santé Conjuguée. 2004;30:29-32 French. 
Journal of Multidisciplinary Healthcare

Dovepress

\section{Publish your work in this journal}

The Journal of Multidisciplinary Healthcare is an international, peerreviewed open-access journal that aims to represent and publish research in healthcare areas delivered by practitioners of different disciplines. This includes studies and reviews conducted by multidisciplinary teams as well as research which evaluates the results or conduct of such teams or healthcare processes in general. The journal covers a wide range of areas and welcomes submission from practitioners at all levels, from all over the world. The manuscript management system is completely online and includes a very quick and fair peer-review system. Visit http://www.dovepress.com/testimonials.php to read real quotes from published authors.

Submit your manuscript here: http://www.dovepress.com/journal-of-multidisciplinary-healthcare-journal 